\title{
Assess the Critical Factors for the Counseling Service System Usage Intention
}

\author{
Hsiu-Hao Liu \\ The Ph.D. Program in Business and Operations Management, College of Management, \\ Chang Jung Christian University \\ No.1,Changda Rd., Gueiren District, Tainan City, 711301, Taiwan \\ E-mail: harry2356969@gmail.com
}

\begin{abstract}
As the most important case management system in the school counseling works, the counseling service system must meet the needs and expectations of the school teacher-counselor (the main users). Semi-structured interviews were used to interview teacher-counselor who have experience in using system in Tainan. The data are recorded and semantic analyzed after interviewing, summarize the critical factors that affect the usage intention of the teachercounselor. The conclusion was to discuss the implications of this research and suggest several future research issues.

Keywords: Usage Intention, Qualitative Research, Counseling Service System, Teacher-Counselor
\end{abstract}

\section{Introduction}

The counseling service system is the most important tool for case management in counseling work in the junior high and elementary schools in Tainan City. The purpose of the system design is to assist school teacher-counselors to care for students and track their psychological development, and hope that students will have good adaptive growth. The school teachercounselors are the main users of using the system. In addition to daily counseling affairs, the school teachercounselors also use the system to record the background information, counseling records, referrals and other operations of the case. In actual use, the school teacher-counselors find that they have encountered difficulties and doubts in the operation of the system, filling in items, and review procedures, and even ethical concerns about the leakage of personal data, which may endanger the relevant rights and protection of the case, and therefore also affect the system usage intention of the school teachercounselors.
Researchers have used self-made questionnaires in previous study. Obtained the result that the school teacher-counselors have low system satisfaction and system usage intention under different background changes. After further analysis, it is found that the two aspects of perceptual ease of use and use attitude will affect the system use willingness. Based on the above research background and qualitative research methods, this study hopes to explore the critical factors that affect the willingness of school teacher-counselors to use the system, and provide suggestions to relevant agencies for improving the system.

\section{Research Methods}

\section{2-1. Research Design}

The structure of qualitative interview questions can be divided into: 1. Structured interviews, which refer to the interview content and questions prepared in advance, also known as standardized interviews; 2. 
Unstructured interviews, refer to the undeveloped interview topics, from the focus of the research participants, and ask questions according to the needs of the interview situation, also known as nonstandardized interviews 3 . Semi-structured interviews, between structured and unstructured, the interview content will be prepared in advance, but the questions will also be adjusted according to the subsequent situation (Lincoln \& Guba, 1985).

This research adopts semi-structured face-to-face formal interviews. Through one-to-one in-depth interviews with research participants, the content and data of the interviews are analyzed, reviewed, aggregated, and summarized to determine the dimensions of critical factors that affect the system usage intention.

\section{2-2. Participant}

In this study, purposive sampling was adopted, and "information-rich cases" were selected as research participants, and a total of four "information-rich cases" were selected as research participants.

The selection criteria for participants in this study are as follows:

- The current position is as a full-time teachercounselors in Tainan Elementary Schools (including public and private).

- $\quad$ These teachers come from different schools and still use the counseling service system.

- These teachers are willing to share personal experiences related to research topics.

Through the researcher's own workplace, direct contact with potential participants, a total of four current full-time teacher-counselors who meet the selection criteria and are willing to accept interviews were invited. The basic information of the participants is shown in Table 1.

Table 1. The basic information of the participants

\begin{tabular}{llll}
\hline No. & Anonym & Seniority & Interview Date \\
\hline A & Tea Bag & 4 years & $2020 / 11 / 3$ \\
B & Little Buck Teeth & 5 years & $2020 / 11 / 4$ \\
C & Agatsuma Zenitsu & 5 years & $2020 / 11 / 6$ \\
D & Chibi Maruko Chan & 3 years & $2020 / 11 / 9$ \\
\hline
\end{tabular}

\section{2-3. Research Tools}

Based on the researcher's previous questionnaire, this study divided the interview content into two parts in view of the critical factors of the system usage intention of the teacher-counselors:

- Explore the main motivations and functions of using system.

- Explore the attraction and resistance factors of using system.

\section{2-4. Data analysis}

Before the interview, an interview outline should be drawn up according to the research question and research purpose. After recruiting the research participants, first send the interview outline to the research participants to discuss the direction and content of the interview. During the interview, the whole process was recorded after seeking the consent of the research participants.

After the interview, the recording files of each research participant were compiled into a verbatim manuscript, then the key points were sorted out and analyzed, and the elements and core themes were summarized. Finally, the interview interpretation was written, and the interview interpretation was sent to the research participants In addition, the "Research Participant Interview Interpretation Confirmation Reply Form" is attached. The research participants are asked to check whether the researcher's interpretation of the interview content is incorrect, and correct any doubtful points for further discussion and clarification. In order to interpret the experience and information of the research participants, the original interviews were interspersed with the description of the thesis when writing the paper. When quoting the content of the interview, if the entire conversation is quoted, it will be presented in italicized block text; if it is a few sentences, it will be framed with " " and changed to italics. The source of the interview content is marked after the quoted paragraph, such as A001: the first English letter is the respondent code, and the last three numbers are the paragraph number of the interviewed content.

When quoting the entire conversation, in order to make the theme more clear, when deleting some interview sentences, "..." will be used. In order to facilitate the smooth reading of the quotation, it will be indicated by [ ] as the text added by the researcher. 


\section{Discussions and Suggestions}

\subsection{Discussions}

The main purpose of this research is to explore the critical factors of the system usage intention of teacher-counselors. First of all, it can be known from the interview content that the main reasons for the participants to use the system are because of the requirements of the system or regulations, and there is no choice. It is only used under circumstances; and the case record is also because the information is passively registered when a case needs to be referred.

It was because the Student Counseling Center asked us to go to a meeting, and then announced that we would all use the online record to fill in and use it. (A001)

...Because we were actually a crisis incident at that time, we had to ask for the tertiary prevention psychiatrist, which is the part of emergency intervention in school services. Then, [the psychiatrist in the school] he reminded us that we must go to the system, and then make such an application. (B001) The tertiary prevention part seems to be the Student Counseling Center. If you want to transfer the secondary prevention case to the tertiary prevention. They stipulate that there must be a record that is uploaded. (C002)

Secondly, the background variables of the teachercounselors are also one of the factors that affect the usage intention. Three participants thought that the frequency of use and the average time of each use would affect the usage intention, because they may become more proficient or unsatisfied as they learn more about the functions of the system.

The reason for frequency of use is closer to the reason for using average time. It refers to the people who use it frequently. He should know more about his advantages and disadvantages. If there are many disadvantages, then of course the less satisfied. If there are many advantages, of course the more satisfaction. (A005)

In addition, two participants believed that age or seniority is also one of the factors that affect the usage intention. Senior teachers with older age or seniority may be less familiar with operating information systems.
Suppose I fill in [the system], or if our senior director or team leader fills in it, they may be less familiar with computer use and it will take longer to fill in. (D002) Finally, we will discuss the positive and negative opinions of participants on the system. As for the attraction factor, two participants thought that the use of systems would help their work. This is a Perceived Usefulness dimension.

Because before you upload [the Case Record], in order to write more detailed information, you must spend some time to do some case review. I think this is helpful for self-organizing and helping, that is, for self-organizing the case. (B005)

Another participant thought that the system responded smoothly, which is the system response time dimension.

For the resistance factor, the three participants said that the review mechanism of the system is suspicious. One participant reflected the inconvenience of the countdown design and the lack of pre-teaching and post-assistance in the system. All of the above can be summarized in the system quality dimension.

...These team leaders, directors, and principals have seen those cases [records] in everything they reviewed, ..., we would not write them in such detail, because we have the principle of confidentiality and there is a problem of funding. I just think why the director, group leader, and principal would also see it? If it's just a review, then what is the purpose of seeing these things, and what is the purpose of these case records and case conceptualizations? (D010)

I think the countdown timer is very unfriendly. I think, I don't know the purpose of its setting? Then again, for the teacher who uses this system for the first time, I think he is also relatively unfriendly, because he only introduced to the teacher-counselors how to use the system at the beginning, and then I reviewed it again. He actually put a teaching manual on it, but the content is trivial and complicated. (B007)

The four participants agreed that the system cannot protect the safety of case data and that the uploading behavior may cause personal information leakage. This is the usage attitudes dimension.

As far as I know, this system is no longer specifically managed, especially his database for storing data. I heard that there is no special person to manage it. Then how do we know that after we fill in the 
information of these cases, Will this information be leaked? Or will it be used? (A009)

As for the confidentiality of this [case records], it should be the unit that requires us to report. They must be themselves, and they must be ethically confidential and protected. Since they have designed this [system], there should be a mechanism. (D012)

\begin{tabular}{|c|c|c|c|c|c|}
\hline Dimensions & $\begin{array}{l}\text { Demographic } \\
\text { Characteristics }\end{array}$ & System Quality & $\begin{array}{l}\text { System } \\
\text { Response Time }\end{array}$ & $\begin{array}{l}\text { Perceived } \\
\text { Usefulness }\end{array}$ & Usage Attitudes \\
\hline Criterias & $\begin{array}{l}\text { 1. Age and } \\
\text { Seniority } \\
\text { 2. System } \\
\text { Using } \\
\text { Frequency } \\
\text { 3. The Average } \\
\text { Using Time }\end{array}$ & 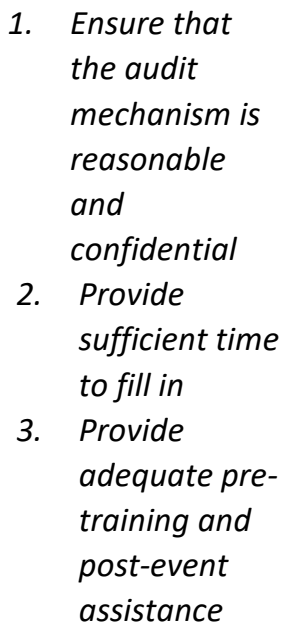 & $\begin{array}{l}\text { 1. Smooth } \\
\text { system } \\
\text { response }\end{array}$ & $\begin{array}{l}\text { 1. Provide a } \\
\text { unified file } \\
\text { format } \\
\text { 2. } \begin{array}{l}\text { Contribute } \\
\text { to case } \\
\text { analysis }\end{array}\end{array}$ & $\begin{array}{l}\text { 1. Have a good } \\
\text { management } \\
\text { authority design } \\
\text { 2. Ensure the } \\
\text { confidentiality of } \\
\text { case information } \\
\text { and counselling } \\
\text { records }\end{array}$ \\
\hline
\end{tabular}

Table 2 The structure of the critical factors for the counseling service system usage intention

\subsection{Suggestions}

Based on the above, the researcher sorted out the critical factors of the system usage intention of the teacher-counselors. There are five main dimensions and eleven criteria (see Table 2).

Compared with the results of previous questionnaire surveys, the usage attitudes has been mentioned all the time, which shows that this dimension requires special attention. Past research can also confirm that there is a positive correlation between usage attitudes and usage intention (Ahn et al., 2007; Juarez Collazo et al., 2014; Wilson, 2019).

Finally, during the interview, many participants mentioned their concerns about participating in this research. Compared with other teachers, the teachercounselors are a closed group. If the upper-level authorities use this research to investigate the identity of the participants, it may affect the rights of many teachers. Therefore, it is recommended that researchers pay more attention to the research description and confidentiality when conducting closed group interviews, so that participants can express their own feelings without scruples.

\section{References}

1. Ahn, T., Ryn, S., \& Han, T. (2007). The impact of web quality and playfulness on user acceptance of online retailing. Information and Management, 44(3), 263-275.

2. Juarez Collazo, N. A., Wu, X., Elen, J., \& Clarebout, G. (2014). Tool use in computerbased learning environments: Adopting and extending the technology acceptance model. ISRN Otolaryngology, 2014, 1-11.

3. Lincoln, Y. S., \& Guba, E. G. (1985). Naturalistic inquiry. Beverly Hills, CA: Sage.

4. Wilson, N. (2019). The Impact Of Perceived Usefulness And Perceived Ease-Of-Use Toward Repurchase Intention In The Indonesian ECommerce Industry. Jurnal Manajemen Indonesia, 19(3), 241-249. 